\section{Gold in Dentistry: Alloys, Uses and Performance}

\author{
Helmut Knosp, \\ Consultant, Pforzheim, Germany \\ Richard J Holliday, \\ World Gold Council, London, UK \\ Christopher W. Corti, \\ World Gold Council, London, UK
}

The current uses of gold in dental applications are reviewed and the major gold-based dental alloys are described with reference to current International Standards. Newer techniques, such as electroforming, are highlighted with suggestions for potential future areas for research and development. The future role of gold in restorative and conservative dentistry is also discussed in the light of increasing competition from alternative materials. It is clear that if longevity, functionality, aesthetics and biocompatibility, together with ease of manufacture are considered as the most important selection criteria, the optimum material for dental restorations is still an approved gold alloy.

\section{Introduction}

Gold is the oldest dental restorative material, having been used for dental repairs for more than 4000 years. These early dental applications were based on aesthetics, rather than masticatory ability. The early Phoenicians used gold wire to bind teeth, and subsequently, the Etruscans and then the Romans introduced the art of making fixed bridges from gold strip. During the Middle Ages these techniques were lost, and only rediscovered in a modified form in the middle of the nineteenth century.

The use of gold in dentistry remains significant today, with annual consumption typically estimated to be approximately 70 tonnes worldwide (1). However, with an increasingly wide range of alternative materials available for dental repairs, it is considered appropriate to review the current gold based technology available today and thereby highlight the exceptional performance that competing materials must demonstrate if they are to displace gold from current uses. New gold-based dental technologies are also highlighted.

\section{Uses of Gold in Dentistry}

In conservative and restorative dentistry, as well as in orthodontics, gold is used either as a pure metal, or alloyed together with noble metals and base metals. This use of pure gold is limited to direct filling of small occlusal cavities and no standard exists for the application and properties of direct filling gold. However, pure gold used in this application is very soft (HV 25), has a very low $0.2 \%$ proof stress (30 MPa) and a large elongation (45\%). As a result it can be very easily cold worked, a necessary requirement for precisely filling a cavity. Since gold fillings do not have high mechanical resistance against masticatory forces, they are only suitable for very small cavities. In recent years pure gold has also been used through the electroforming process. Electroformed inlays and onlays are suitable to be cemented into cavities after they have been veneered with porcelain. Tooth restorations such as porcelain veneered copings for crowns and bridgework can be electroformed with pure gold. Unfortunately, no standard yet exists for this process, which is rapidly becoming an established mainstream technique in modern dentistry.

A more common technique in conservative dentistry is cementing investment cast gold alloy inlays and onlays into cavities. Mostly commonly used alloys are based on 65 - 75\% gold, fulfilling the international standard EN ISO 1562:1995, Table1. Alloys with lower gold contents corresponding to EN ISO 8891:2000 can also be used. The standards EN ISO 1562 and 8891 are valid for both cast gold alloys, with different contents of gold and platinum group metals, Table 2 .

Inlays, onlays and partial crowns from high gold alloys can 


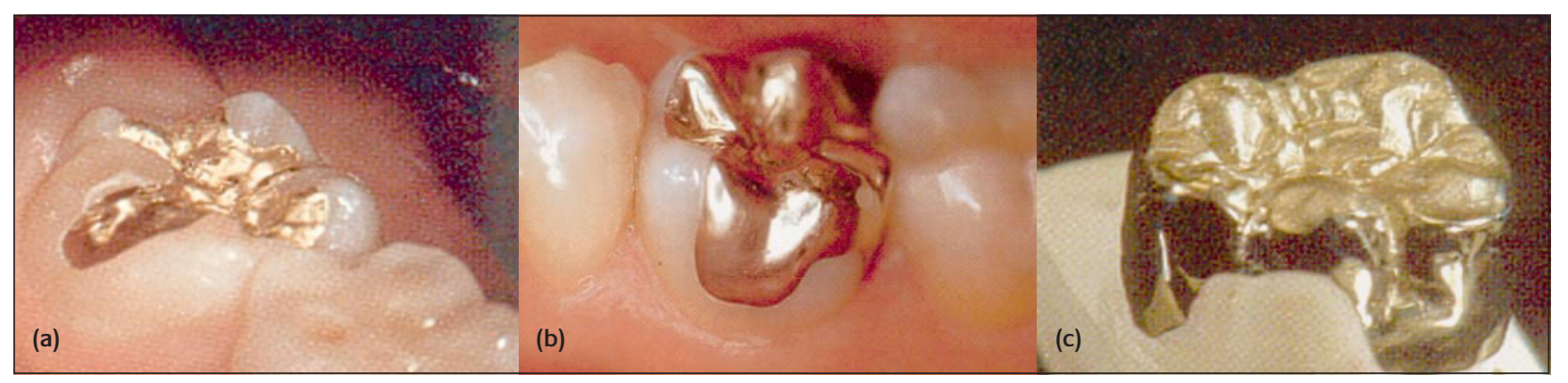

\section{Figure 1}

Castings of inlay, onlay and partial crown respectively as examples of conservative dental treatment. (a) Gold inlay in molar 47 (b) Gold onlay on molar 15 (c) Partial crown for molar 36 on the model die. (Pictures courtesy of Hans H. Caesar, Zahntechnikermeister, Ludwigsburg)

\section{Table 1}

Dental gold alloys - compositions and indications (uses)

\begin{tabular}{|c|c|c|c|c|}
\hline Alloy Group & $\begin{array}{l}\text { Gold content } \\
\%(m / m)\end{array}$ & Others $\%(\mathrm{~m} / \mathrm{m})$ & $\begin{array}{c}\text { ISO EN } \\
\text { Standards }\end{array}$ & Indications* \\
\hline 1 & $99.9-99.99$ & - & - & $\mathrm{A}, \mathrm{M}$ \\
\hline 2 & $97.9-98.3$ & 1.7 Ti, Ir, Rh, Nb & 9693 & $C, D, E$ \\
\hline 3 & $75-90$ & 10 - 20 PGMs, In Sn, Fe, Re, Ag, Cu, Zn, Ta, Ti, Mn & 9693 & $C, E$ \\
\hline 4 & $60-75$ & approx. 10 PGMs, 10 - 25 Ag, Cu, In, Sn, Zn & $\begin{array}{l}1562 \\
9693\end{array}$ & $B, C, D$ \\
\hline 5 & $65-75$ & 5 - 10 PGMs, 5 - 20 Ag, Cu, Zn & 1562 & $\mathrm{~B}, \mathrm{D}, \mathrm{E}, \mathrm{F}, \mathrm{G}, \mathrm{H}, \mathrm{L}$ \\
\hline 6 & 60 & 40 PGMs & - & $\mathrm{H}, \mathrm{l}, \mathrm{N}$ \\
\hline 7 & $40-60$ & 5 - 10 Pd, 10 - 30 Ag, Pt, Cu, Zn, Ir & 8891 & $B, D, L$ \\
\hline 8 & $40-60$ & 20 - 40 Pd, 0 - 20 Ag, In, Sn, Cu, Ga, Ir, Re, Ru & 9693 & C \\
\hline 9 & approx. 15 & approx. 50 Pd, approx. 20 Ag, In, Sn, Ga, Ir, Re, Ru & 9693 & C \\
\hline 10 & $2-12$ & 30 - 60 Ag, 20 - 45 PGMs, Cu, Zn, Ir, & 8891 & $B, F, L$ \\
\hline 11 & $0.1-2$ & 50 - 60 Pd, 25 - 40 Ag, In, Sn, Ga, Ir, Re, Ru & 9693 & C \\
\hline 12 & $0.1-5$ & 70 - 80 Pd, Sn, Cu, Co, Ga, Ir, Re, Ru, Pt & 9693 & C \\
\hline 13 & $10-80$ & 0 - 20 PGMs, 0 - 70 Ag, Cu, Sn, In, Zn, Co, Ni, Mn & 9333 & K \\
\hline
\end{tabular}

* A Electroforming, B Inlays, Onlays, Fixed Crown- and Bridgework as Full Cast and for Polymer Veneers, C Fixed Crown- and Bridgework for Porcelain Veneers, D Telescopic Crowns and Milling Work for Removable Dentures, E CAD/CAM, F Orthodontic Wire, G Clasp Wire, H Prefabricated Attachments, I Root Canal Posts, K Solders, L Partial Denture Framework, Cast Attachments, Plates, Connecting Bars, Saddles and Splints, M Gold Foil for Direct Fillings, N Cast-On Technique

PGMs = Platinum Group Metals

be precisely fabricated in the dental laboratory with an excellent marginal fit and longevity of many years, Figure 1. Full cast or partially veneered crowns are mostly used for posterior teeth because gold (as well as other metallic materials) should not be visible in the anterior area.

Four types of alloys are defined in EN ISO 1562 and 8891 respectively, covering a wide range of uses in conservative and restorative dentistry and orthodontics. The most widely used is the Type 4 alloy, which is suitable for all kinds of extra-highstrength crown- and bridgework as full cast and/or polymer veneered. Orthodontic and clasp wires, attachments, partial denture framework, plates, bars, saddles and splints can be cast or prefabricated from Type 4 alloys. In addition, telescopic crowns and milling work are appropriate uses of this alloy.

Porcelain-fused-to-metal restorations have become a widespread technology in the last 20 to 30 years (2). Gold alloys with special properties, including high sag resistance and compatible coefficients of thermal expansion to porcelains, have been developed fulfilling the necessary requirements for fixed crowns and long span bridges with porcelain veneers. The standard EN ISO 9693:2000 describes the requirements for these alloys, which are not divided into different types nor have a prescribed gold content. This standard is valid for noble and base metal alloys as well as for the suitable porcelains, Table 3.

For all groups of dental gold alloys, lower melting point gold solders should be available with a composition as similar as possible to the alloy to be soldered in order to get a high bond strength. The current standard for all kinds of dental solders is EN 29333/ISO 9333:1992 - 'Dental Brazing Materials' - which requires a minimum bond strength of the soldered joint of $350 \mathrm{MPa}$. An increasingly used joining method is laser 


\section{Table 2}

Requirements for dental casting gold alloys with minimum gold content of $65 \%(\mathrm{~m} / \mathrm{m})$ and minimum content of gold and PCM's of 75\% $(\mathrm{m} / \mathrm{m})$ according to EN $1 S O 1562$ and for dental casting alloys with noble metal content of at least $25 \%(\mathrm{~m} / \mathrm{m})$ but less than $75 \%(\mathrm{~m} / \mathrm{m})$ according to EN ISO 8891

\begin{tabular}{|c|c|c|c|c|c|}
\hline \multirow[t]{2}{*}{ Type of alloy } & \multicolumn{3}{|c|}{$0.2 \%$ Proof stress (MPa) } & \multicolumn{2}{|c|}{ Elongation after fracture (\%) } \\
\hline & $\min$. & max. & $\begin{array}{l}\text { hardened } \\
\text { min. }\end{array}$ & $\begin{array}{l}\text { softened } \\
\text { min. }\end{array}$ & $\begin{array}{l}\text { hardened } \\
\text { min. }\end{array}$ \\
\hline 1 & 80 & 180 & - & 18 & - \\
\hline 2 & 180 & 240 & - & 12 & - \\
\hline 3 & 240 & - & - & 12 & - \\
\hline 4 & 300 & - & 450 & 10 & 3 \\
\hline
\end{tabular}

Type 1: low-strength - for castings subject to very slight stress, e.g. inlays

Type 2: medium-strength - for castings subject to moderate stress, e.g. inlays and onlays

Type 3: high-strength - for castings subject to very high stress, e.g. onlays, thin cast backings, pontics, full crowns and saddles

Type 4: extra-high-strength - for castings subject to very high stress and thin cross-section, e.g. saddles, bars, clasps, thimbles, unit castings and partial frameworks

Table 3

Requirements for metal-ceramic dental restorative systems according to EN ISO 9693

\begin{tabular}{ccc}
$\begin{array}{c}\mathbf{0 , 2} \% \text { Proof } \\
\text { stress (MPa) } \\
\text { min. }\end{array}$ & $\begin{array}{c}\text { Elongation } \\
\text { after fracture } \\
\text { (\%) min. }\end{array}$ & $\begin{array}{c}\text { Metal-ceramic } \\
\text { bond strength } \\
\text { (MPa) min. }\end{array}$ \\
\hline 250 & 3 & 25 \\
\hline
\end{tabular}

welding, for which a German standard DIN 13972-2:2002 'Suitability of identical and similar metallic dental materials for laser welding' now exists. This standard is valid for all dental alloys and also requires a minimum bond strength of $350 \mathrm{MPa}$ for the welded joint.

One further application for gold in dentistry is in plating or gilding other metallic components. Partial dentures are mainly cast from cobalt/chromium alloys. Fixing to the residual dentition can be performed either by clasps which are fabricated in one-piece cast together with the connector part or by telescopic crowns, which have to be soldered or welded onto the connector. In order to mask the white color of the cobalt/chromium alloy, and especially to visually mask the joint, a yellow gold layer is deposited onto the surface of the denture by using cyanidic gold electrolytes based on $\mathrm{K}\left[\mathrm{Au}(\mathrm{CN})_{2}\right]$. If gilding is used, the thickness of the layer is only 0.1 to $0.2 \mu \mathrm{m}$, and therefore the durability may not be acceptable because of abrasion occurring during use. Gold plating with layers of $5 \mu \mathrm{m}$ thickness and greater are therefore recommended. Plated layers are relatively hard (HV140 - 180) and have a density of 16.5 to $17.5 \mathrm{~g} / \mathrm{cm}^{3}$. If a cobalt alloyed electrolyte is used, the composition of the deposit is approximately $99 \%$ gold and 1\% cobalt. Similarly, prefabricated attachments and springs for orthodontic appliances are made of stainless steels alloyed with nickel, chromium, cobalt, manganese and partly with titanium. These appliances can also be gold gilded or plated using cyanidic gold electrolytes.

\section{Gold Alloys and Properties}

In order to examine the gold alloys specified for each application in Table 1, a characteristic alloy has been extracted from each group and presented with its total composition, together with the most important physical properties, Table 4.

Due to the stress generated by masticatory forces, alloys for dental restoration must have adequate mechanical properties. Alloys for indication B, Type 4 as well as C, D, E and $L$ (see table 1) must have a high proof stress, and a suitable elongation in order to prevent cracks. Alloys for indications $F$ and $G$ gain additional strength through work hardening during the wire drawing process. Orthodontic and clasp wires must keep a high elongation for bending ability. For casting gold alloys, the melting range should be as low as possible. Alloys for porcelain veneers must have a solidus temperature around $100 \mathrm{~K}$ higher than the firing temperature of the used dental porcelain, in order to ensure that the cast framework does not sag during firing. High fusing porcelains need firing temperatures between 900 and $980^{\circ} \mathrm{C}$, while low fusing porcelains are fired at a maximum of $800^{\circ} \mathrm{C}$. Sag resistance is not only dependent upon the solidus temperature but varies considerably with the content of palladium. A minimum content of about 5\%Pd in high gold alloys is recommended.

Another important property for porcelain-fused-to-metal alloys is the coefficient of thermal expansion (CTE) which must be compatible to that of the porcelain to avoid internal stresses in the porcelain veneer during cooling from the firing temperature. Porcelain can withstand higher compressive stresses than tensile stresses, and it is therefore desirable that the thermal expansion of the alloy should be slightly above that of the porcelain. In this way compressive stresses are generated in the porcelain shell during cooling. Thermal expansion of porcelain, in contrast to that of a metal or an 


\section{Mige:

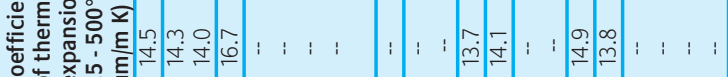

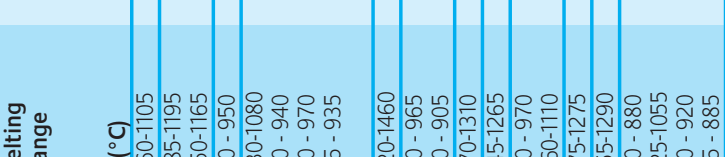

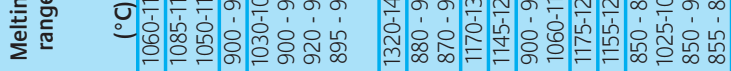

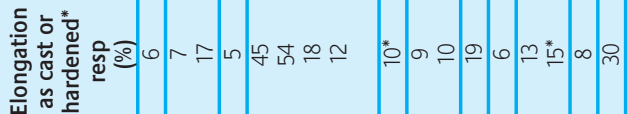

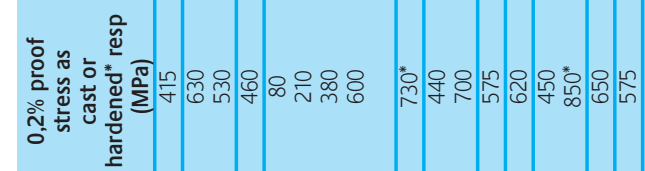

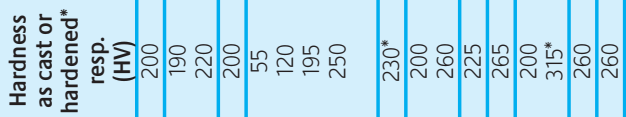

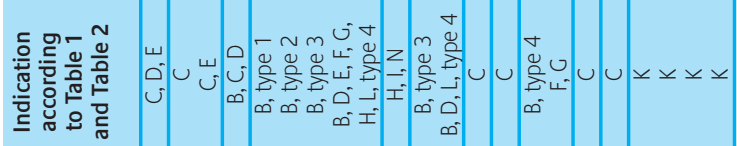

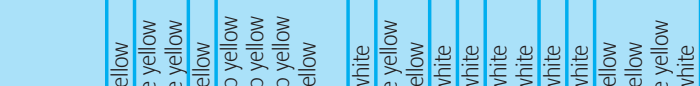

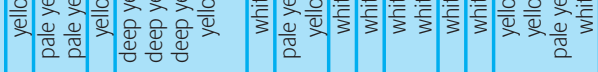

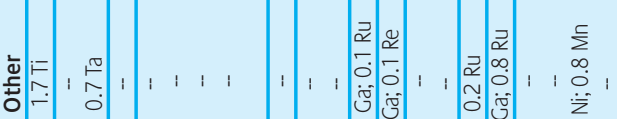

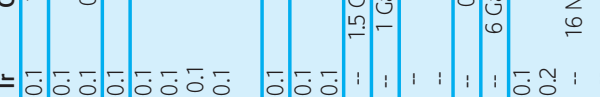

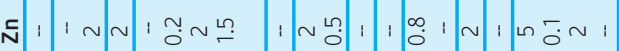

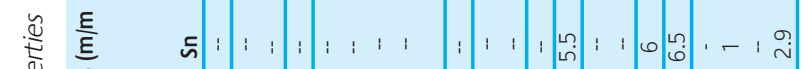

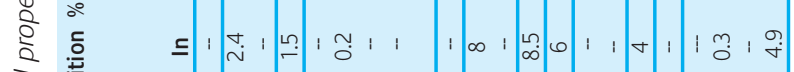

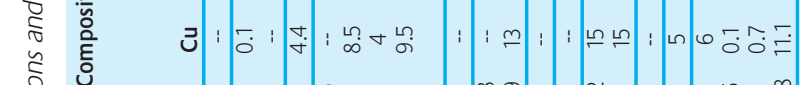

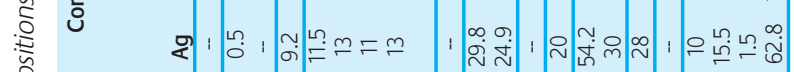

है $\quad$ है

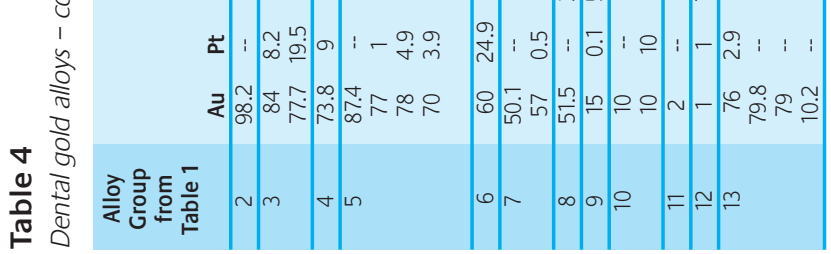
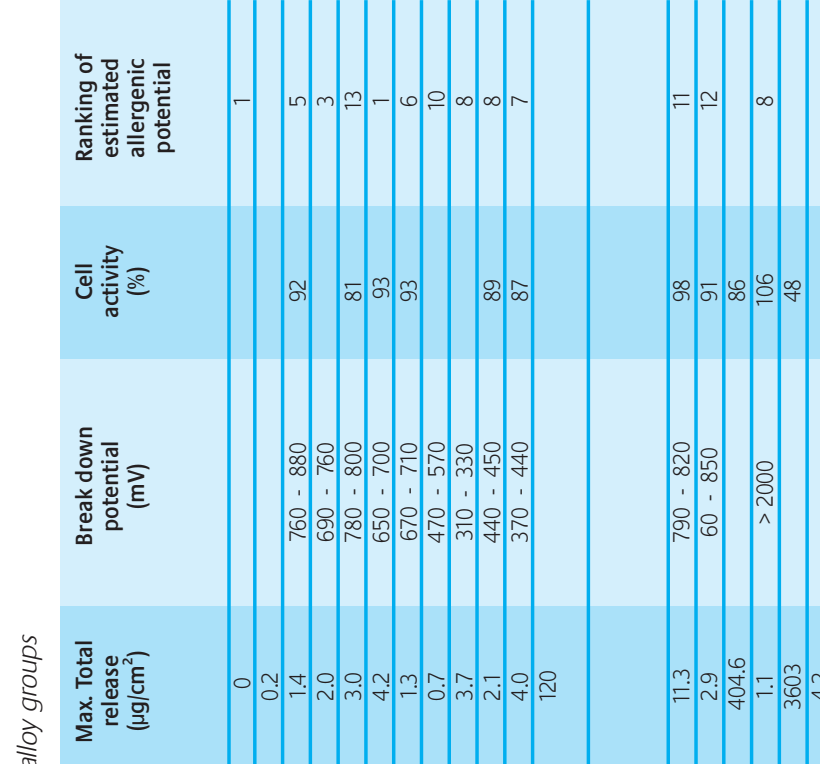

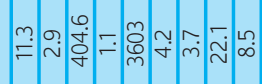

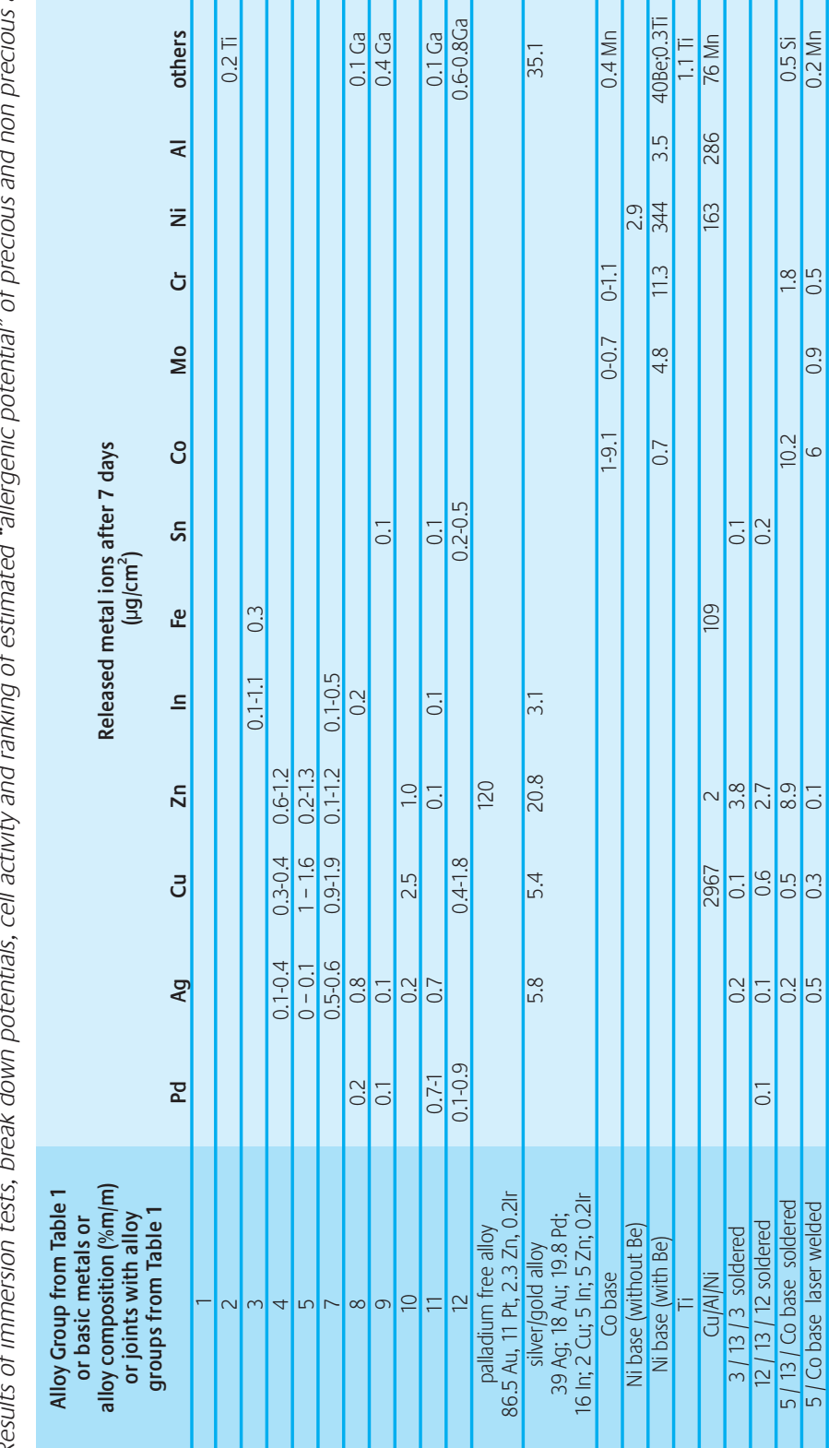

Gold Bulletin 2003 • 36/3 


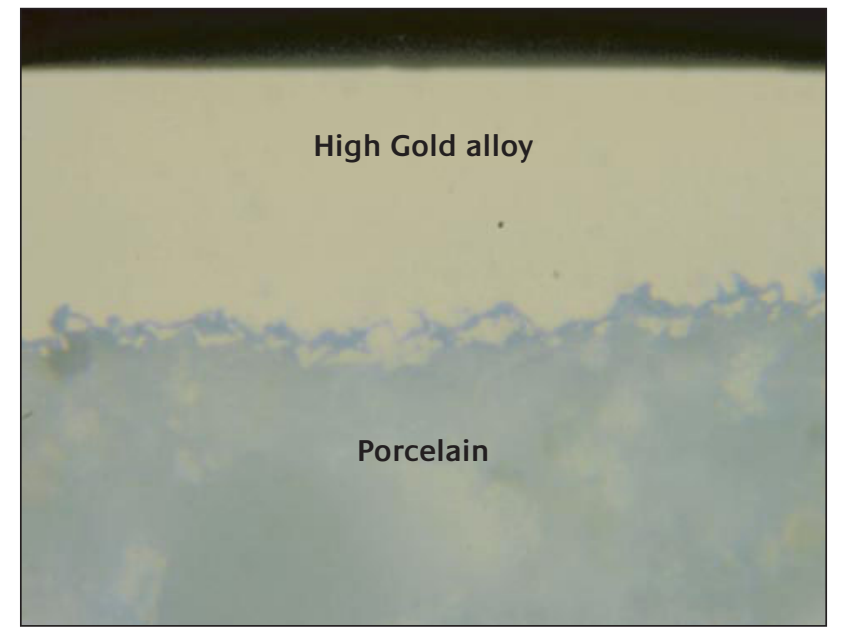

Figure 2

Interface between porcelain and a high gold alloy; thin oxide layer less than $1 \mu \mathrm{m}$

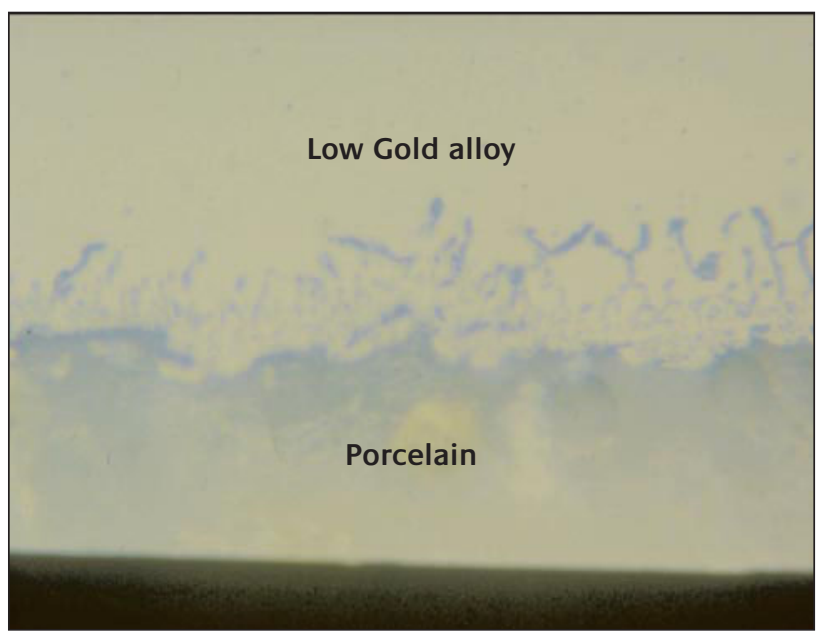

Figure 3

Interface between porcelain and a low gold alloy; thick oxide layer of approximately $100 \mu \mathrm{m}$

alloy, is not independent of the cooling rate. Slow cooling rates after firing lead to a higher thermal expansion of porcelain, so a higher CTE of the alloy can be compensated by slower cooling. The CTE's of high gold/platinum alloys, are mostly balanced to high fusing porcelains. For the low fusing porcelain, only high gold/silver/PGM alloys are available.

The reason for the presence of base metals, such as copper, indium, and tin even in such small quantities in high gold alloys, is the necessary precipitation hardening, as well as the ability to bond the porcelain to the metal surface. The oxides of the base metals are formed at the surface of the alloy during the firing cycle. The required bond strength is specified in EN ISO 9693 (Table 3) and can be obtained by means of a very thin oxide layer of less than $1 \mu \mathrm{m}$ on the surface of the alloy. In alloys with a higher content of base metals, because of the lower content of gold and PGM's, oxide layers are thicker and lead to unsatisfied aesthetics and in bad cases to cracks and breakoffs in the porcelain veneer. Figures 2 and 3 show the interface between porcelain and a high gold alloy with a very low content of base metals and a low gold alloy with a high content of base metals respectively.

An interesting new variation on these established dental alloys is the recent development by a major alloy producer of an extremely high gold content alloy (99.7\% Au), with small additions of indium (0.2\%) and zinc (0.1\%) (3). It has been claimed that the high gold content means that this alloy imparts a warm, dentin-like colour to the porcelain. Because of this feature, there is a complete elimination of gingival 'black line disease' associated with traditional porcelainfused-to-metal fixed restorations. The lower strength of this alloy means that it is not suitable for long span bridgework. For several years, other extremely high gold content alloys (98.2\% Au) with additions of Ti, Ir, Rh and/or Nb have been used (see Table 4). They are fine grained, have a sufficient strength for crown and bridgework, but they have to be melted and cast under a protective gas atmosphere (4).

\section{Electroforming}

The electroforming process with pure gold was first used in conservative dentistry for inlays in 1961 and has been reported in Gold Bulletin previously (5). The process itself has been known for more than 150 years within the electroplating industry, particularly in the production of jewellery, decorative items and watch fabrication. During the last 10 years the electroforming process has been increasingly used in conservative and restorative dentistry. The major advantage of the process is that the production of a very precise coping of pure gold, which does not change its dimensions during firing on porcelain, can be achieved with only one piece of equipment and there is no further need of wax modelling, investing, preheating of moulds and casting.

Electroforming baths suitable for dental restorations are non-cyanide and contain a gold sulfite electrolyte corresponding to the chemical formula:

$$
\left[\mathrm{Au}(\mathrm{Amin})_{2}\left(\mathrm{SO}_{3}\right)_{2}\right]^{3-} \Leftrightarrow\left[\mathrm{Au}(\mathrm{Amin})_{2}\right]^{+}+\left(2 \mathrm{SO}_{3}\right)^{2-}
$$

Electroformed pure gold has a hardness of $100 \mathrm{HV}$ and a fineness between 99.9 and $99.99 \%$. The crystal structure of the deposit shows a very fine grain size of less than $1 \mu \mathrm{m}$. After firing on porcelain, recrystallisation leads to a very acceptable average grain size of $50 \mu \mathrm{m}$, Figure 4a. Cast pure gold on the contrary is very coarse grained with a typical grain size of $400 \mu \mathrm{m}$, Figure 4b. 
At first sight, it may appear somewhat contradictory to the previous described properties of gold alloys that the relatively low hardness of electroformed pure gold, the absence of oxidable base metals and the CTE of $15.2 \mu \mathrm{m} / \mathrm{mK}$ permits the fabrication of a porcelain-fused-to-metal framework. In fact, the use of high or low fusing porcelains with CTE's between 13.8 and $17.2 \mu \mathrm{m} / \mathrm{mK}$ generally has no influence on the successful production of a porcelain-fusedto-metal prosthesis based on electroforming. The reason for this is probably that stresses arising in the porcelain during cooling down from the elevated firing temperature will be absorbed by the ductile pure gold. The bond strength between porcelain and electroformed pure gold is acceptable. Bond strength tests (three point bending tests according to EN ISO 9693) have yielded results of more than $30 \mathrm{MPa}$ (6). This value can be easily improved by using a gold paste consisting of powders of fine gold and ceramic, which is sintered upon the gold surface as a thin sponge like layer and provides an intimate mechanical interlock effect between porcelain and gold. A further advantage of electroformed parts is the absence of dark oxides, which are formed during porcelain firing on the surface of alloys, Figure 5.

There are a wide range of dental applications for electroformed pure gold in crown- and bridgework. Various methods are available to join cast pontics together with electroformed copings. These methods include sintering, lasering/soldering, sticking, cast-on and galvanizing-in techniques. It is considered that the sintering technique with electroformed bridgework is the most precise method with strengths similar to those achieved by a full cast bridgework. Electroformed copings used in modern telescopic removable prostheses and fixed prostheses, are playing an important role as a secondary structure. Long span bridges from one piece castings are critical with respect to their fit at the abutment crowns. To overcome this problem, copings are positioned onto the prepared stumps and cemented to the framework within the mouth. This method is very important in the case of implants, because they can become detached if they are exposed to lateral stresses.

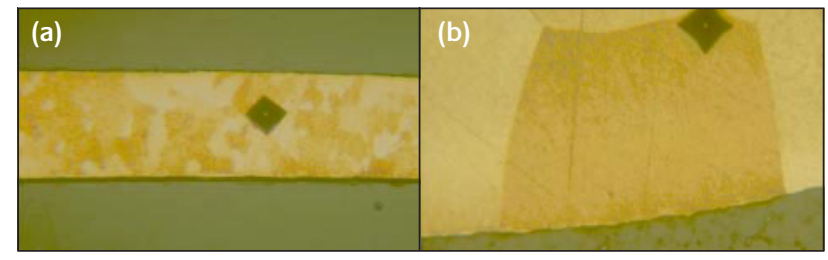

\section{Figure 4}

(a) Crystal structure of electroformed pure gold after porcelain firing with impression following hardness testing; average grain size $50 \mu \mathrm{m}$. (b) Crystal structure of cast pure gold with impression after hardness testing; average grain size $400 \mu \mathrm{m}$

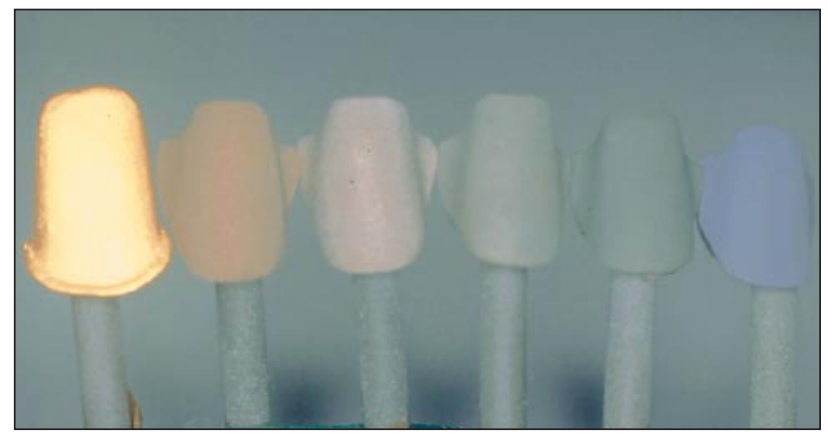

\section{Figure 5}

Oxide colours of different dental alloys compared to electroformed pure gold. From the right: titanium, cobalt/chromium; palladium base, two different high gold alloys, electroformed pure gold

\section{Biocompatibility - Definition, Testing and Standards}

Besides functional performance and aesthetics, biocompatibility is a third important requirement for dental restorative materials. Where dental restorations are based on the use of different alloys, there is the obvious potential for oral polymetallism. Indeed, two alloys of different composition have different electrochemical potentials, and inevitably induce corrosion, with the subsequent release of metal ions into the tissue. The ion release from metallic prostheses and implants is the main cause of any unwanted primary and secondary reactions in the human body. This phenomena may lead to the deterioration of dental devices, and in the worst case, may cause prosthesis failure or fracture.

For several years, research teams have been attempting to find a correlation between the corrosion behaviour and the cytotoxic effects of dental alloys. However, it is reasonable to state that the relationships between corrosion, the released corrosion products and the cytotoxic response have not yet been clearly established. Different ions are released at different rates from the alloy: gold, indium and palladium do not dissolve in commonly used cell culture media, whereas silver, copper, gallium, nickel and zinc are dissolved after a defined period under identical experimental conditions. However, gold and platinum show no dissolution in artificial saliva, but other ions especially indium, copper, zinc, gallium, cobalt, and nickel, are detected. The dissolution behaviour of alloys can be different under other experimental conditions and it is generally recognized that the nature, rather than the quantity of released corrosion products, is important for cytocompatibility.

To predict the biocompatible properties of a material, it is necessary to obtain information about dissolution behaviour, cytotoxicity and, with regard to metals and alloys in the mouth, data about electrochemical potentials. 
A large number of tests have been developed with this aim in mind and elements of them are defined in standards which must be met in order to confirm to the EU Directive 93/42/EWG.

Historically, immersion tests have been commonly used to detect the release of metal ions in a solution of artificial saliva. This in vitro test is intended to simulate the type of corrosion occurring in the human mouth. The artificial saliva consists of deonized water containing lactic acid and sodium chloride with a $\mathrm{pH}$ of 2.3. Cast specimens of the alloy to be tested are suspended in glass containers with the artificial saliva. After 7 days the solutions are analysed for all elements originally contained in the alloy. Discoloration on oral metallic restorations can occur either from inhomogenous alloys, surface porosities or if different alloys with different electrochemical potentials are joined together. Less noble alloys work as an anode whereas higher noble alloys are cathodes with the saliva as electrolyte. For instance, the cathodic deposit of copper and silver discolors the higher noble alloy as a result of copper and silver sulfide formation.

The immersion test is the mostly commonly used of all standardized and recommended test methods. A total release of metal ions during the 7 days storage in the corrosion medium should not exceed $100 \mu \mathrm{g} / \mathrm{cm}^{2}$, although this limit is not obligatory. In Table 5, test results from different groups of precious and non-precious alloys, as well as from soldered and welded joints are shown (7-9). It can be seen that high gold alloys show a moderate ion release, except for a palladium-free alloy with a very high release of zinc ions. Research suggests that palladium seems to be necessary in gold alloys in order to prevent corrosion of base metals. This is confirmed by the relatively low ion release from palladium and silver/palladium based alloys. Generally it is found that copper, zinc and indium ions are passing into solution. High gold alloys have been studied in order to find an alloy resistant to corrosion and it has been found that there are alloys containing 92-93\% of gold, 3-4\% of palladium and additional quantities of platinum, silver and tin that have a total ion release of less than $0.1 \mu \mathrm{g} / \mathrm{cm}^{2}$ after seven days.

In terms of base metal alloys, large differences in metal ion release have been observed. While pure titanium and beryllium-free nickel base alloys show very acceptable results, a considerable release of cobalt ions from cobalt-base alloys is found. Extremely high corrosion occurs in berylliumcontaining nickel-based alloys, and much more in copperbased alloys, which can never be recommended for use in the oral environment.

Discoloration of a dental alloy is not only due to an electrochemical reaction. It can be caused by a chemical reaction on the surface of the alloy, if a surplus of metals reacting with sulphur and oxygen, e.g. silver and copper are present. Discoloration is only minimised if the total quantity of gold and PGM's present in the alloy exceeds $60 \%$.

Metals and alloys in the human mouth possess electrochemical potentials in saliva. Electrochemical tests are carried out by measuring the electrochemical potential of an alloy against a reference electrode of saturated calomel. Electrochemical potentials in the mouth can be measured between two different alloys or between a metallic restoration and a gold cube as a reference electrode placed on the oral mucosa. Low breakdown potentials can lead to corrosion. In Table 5, the breakdown potentials for the different groups of dental alloys are summarized. Measurements have been performed by anodic polarisation in an electrolyte containing $0.9 \%$ of sodium chloride at $\mathrm{pH}$ 7.4. The higher the potential, the more noble the metal or alloy. It is obvious that the content of gold in an alloy plays the most important role, i.e. the higher the gold content, the higher the breakdown potential. A general guideline is that the breakdown potential should not be less than $600 \mathrm{mV}$. This can be achieved with gold alloys containing more than $40 \%$ of gold. The breakdown potentials of gold/copper alloys are much higher than those of the palladium/copper alloys at the same content of gold and palladium, respectively (10). It is clear that the maximum potential of the gold alloys is reached at $40 \%$ gold content. Absolute numbers of breakdown potentials described in Table 5 vary because of different electrolytes.

The breakdown potentials of non-precious alloys are very different, especially those of nickel based alloys, which show a wide variation. The reason for this is that non-precious alloys need a passivation layer on their surface in order to avoid corrosion. In contrast, gold and high gold alloys do not need any passivation, since they are noble by nature. To form a passivation layer, non-precious alloys need a very dense oxide layer with strong adherence. For cobalt- and nickel-based alloys, the combined chromium and molybdenum content should be a minimum of $30 \%$. Titanium forms a very strong passivating oxide layer in oxygen-containing atmospheres, leading to its excellent biocompatibility.

Cell proliferation tests, according to the previously described standards, have been carried out on the alloy groups in Table 5. The percentage of proliferation in a 75\% eluate concentration is calculated as cell activity. There appears to be a slight correlation to the total release of metal ions, which is more obvious for the nickel- and copper-based alloys.

In terms of the potential of allergenic reaction of dental alloys, an epidemiological study has been carried out using patch tests (7). As a result of these tests a ranking of the estimated "allergenic potential" has been attempted for the alloy groups in Table 5. No alloy or group of alloys appear to 
be completely free of "allergenic potential". Except for the nickel group, however, no statistically significant differences between a particular group have been found.

In another series of patch tests, gold alloys with different contents of nickel and palladium were assessed and the results compared with the release of nickel and palladium ions, Table 6 (11). A correlation was found between allergic reactions of patients and release of nickel ions. Although no palladium ions have been released in this test, it is considered that there is a cross allergy between nickel and palladium, and that if a patient is allergic to nickel, no palladium containing material should be incorporated.

In a recent study, the technical and clinical properties of crown materials were compared and the results are shown in Table 7. It is clear that electroformed crowns exhibit superior performance over other systems, particularly in terms of biocompatibility and aesthetics, with porcelain veneered cast gold crowns ranked in second place (12).

\section{The Future of Gold in Dentistry}

The historical development work concerning the use of gold in conservative and restorative dentistry has provided the industry with a wide array of gold-based dental alloys suitable for application in an extensive range of uses. If longevity, functionality, aesthetics, and biocompatibility, together with ease of manufacture are considered as the most important requirements, the optimum material for dental restorations is still a well-approved high gold alloy. It is no co-incidence that in all testing and development of competing materials, gold is always defined as the standard material to be judged against. It is interesting to note that if practising dentists are asked what type of material for a restoration they prefer for themselves, with few exceptions the answer is always gold (13).

Nonetheless, attention is increasingly focusing on the extensive range of alternative materials. These new materials include titanium and cobalt/nickel base alloys and all-ceramic crowns. The latter have excellent aesthetic properties, but do not have the long-term clinical approval that gold has. For example, zirconia has only passed clinical tests during the last 4 years. In addition, the CAD/CAM techniques associated with the use of these materials are, in many instances, prohibitively expensive. Furthermore, the problems of poor aesthetics often associated with porcelain-fused-to-metal techniques might be addressed through the use of extremely high gold content alloys, which have recently been patented. It is considered that as CAD/CAM technology progresses, special high gold alloys should be developed, which are well suited to milling and grinding operations and have sufficiently high strength for long span bridges and small cross sections (14).

Of the other competing materials, problems encountered with casting titanium remain, preventing widespread use of this material. Long-term use of cobalt/chromium alloys are increasing, and there are fewer problems with casting compared to titanium. In Table 8, advantages and disadvantages of different restorative materials are compared with gold. Besides long term clinical approval and longevity, the most important advantages of gold alloys are easy workability, biocompatibility, aesthetics and maximum range of indications.

The development of electroforming technology with pure gold offers new opportunities for future research. For highly stressed parts in dental restorations, electroformed pure gold is still too soft and thus has limited uses. Efforts have been made in recent years to develop increased strength through dispersion strengthening by incorporating a suspension of ceramic particles (15). Another area for electroforming research may focus on the deposition of multilayers by electrochemical structure modulation. Both of these research efforts should have the objective of developing thick deposits of pure gold with high strength (15).

\section{About the Authors}

Dr Helmut Knosp has been involved in R\&D of precious metals dental alloys, materials and equipment since 1968, initially with Degussa $\mathrm{GmbH}$. He joined C. Hafner $\mathrm{GmbH}$ in 1981 in Pforzheim as a technical director. He obtained his doctorate at the University of Stuttgart and was for several years with the Max-Planck-Institute for Metals Research, Stuttgart, and Carl Zeiss, Oberkochen. Now in retirement he

\section{Table 6}

Correlation between nickel ion release and number of allergic reactions

\begin{tabular}{|c|c|c|c|c|c|c|c|c|}
\hline \multicolumn{6}{|c|}{$\begin{array}{c}\text { Compositions of alloys } \\
(\% \mathrm{~m} / \mathrm{m})\end{array}$} & \multicolumn{2}{|c|}{$\begin{array}{c}\text { Ion release } \\
\mu \mathrm{g} / \mathrm{cm}^{2} \text { over } 7 \text { days }\end{array}$} & \multirow{2}{*}{$\begin{array}{l}\text { Number of } \\
\text { allergic reactions } \\
(n=100)\end{array}$} \\
\hline $\mathrm{Au}$ & $\mathrm{Ag}$ & $\mathrm{Cu}$ & $\mathrm{Zn}$ & Pd & $\mathrm{Ni}$ & $\mathrm{Pd}$ & $\mathrm{Ni}$ & \\
\hline 76 & - & 16 & 2 & - & 6 & - & 0.22 & 17 \\
\hline 75 & - & 7.5 & 2 & 13.5 & 2 & 0.00 & 0.03 & 3 \\
\hline 58.5 & - & 25.5 & 9 & - & 7 & - & 0.42 & 26 \\
\hline 58.5 & 18 & 6.6 & 0.9 & 14 & 2 & 0.00 & 0.02 & 6 \\
\hline 37.8 & - & 40 & 10.4 & - & 11.8 & - & 14.3 & 27 \\
\hline
\end{tabular}




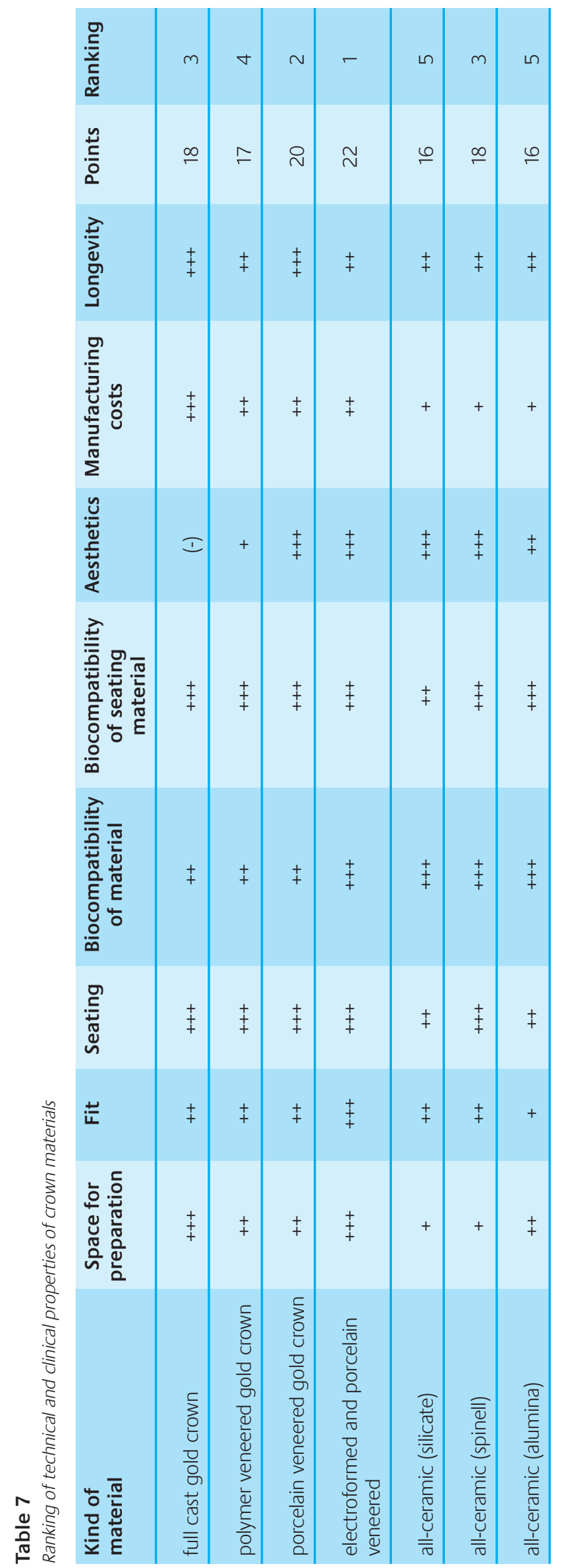

is still a member of the advisory board of the FEM, the Research Institute for Precious Metals and Metals Chemistry, Schwäbisch Gmünd, Germany.

Dr Richard Holliday is currently Industrial Applications Manager at World Gold Council, London. His responsibilities include management of the Council's GROW (Gold Research Opportunities Worldwide) Programme, focused on research and feasibility studies with the potential to lead to new applications for gold. He is Chairman of the Materials Technical Committee for the GOLD2003 Conference to be held in Vancouver later this year.

Dr Christopher Corti is Director, International Technology, World Gold Council and has over 23 years, experience in precious metals technology development and industrial application. A former technical Director at Johnson Matthey Colour and Print Division, he has been at World Gold Council since 1994 and is Editor of the journal Gold Bulletin.

\section{References}

1 'Gold Survey 2002' Gold Fields Mineral Services Ltd, London, 2002

2 'Gold Alloys for Porcelain-Fused-to-metal Dental Restorations', Randall M. German, Gold Bulletin, 1980, 13 (2), 57-62

3 '24 Karat Gold and the Art of Aesthetics' I.E. Shuman, Dentistry Today, 2001, 204

4 'Dental Alloy with a High Gold Content', European Patent EP 0691123 (1997)

5 'Electroformed Gold Dental Crowns and Bridges' Matthijs M.A. Vrijhoef, Adam J. Spanauf, Heinz H. Renggli, Gerard A. Somers and Horst L. Wismann, Gold Bulletin, 1984, 17 (1), 13-17

6 'Evaluation of Bond Strength between an Electroformed Gold Coping and Porcelain', Craig A. Sirota, Thesis, Harvard School of Dental Medicine, Boston, Massachusetts (1998)

7 'Verträglichkeit von Dentallegierungen', Institut der Deutschen Zahnärzte, Deutscher Ärzte Verlag, Köln (1998)

8 Lenz, E., Jena, private communication

9 Knosp, H., Pforzheim, unpublished tests

10 In accordance to Gerischer and Bockris in: Frankfurter Symposium 'Dental-legierungen heute', Fachvereinigung Edelmetalle, Frankfurt (1984)

11 CEN/TC 283, 'Precious Metals Applications in Jewellery and Associated Products', Test results for EN 1811 (1998): 'Reference Test Method for Release of Nickel from Products intended to come into Direct and Prolonged Contact with the Skin'

12 Wirz, J. and K. Jäger, 'Evaluation of Commonly used Crown Systems' QDT (1999) 193

13 Christensen, G., Ästhetische Zahnmedizin 2 (1999) 80

14 Bohm, U., Quintessenz Zahntechnik, 28, 2(2002) 114

15 Zielonka, A. und Fauser H., 'Advanced Materials by Electrochemical Techniques', Z. Phys. Chemie 208 (1999) 195 
Table 8:

Advantages and disadvantages of different materials and techniques for dental restorations

\begin{tabular}{|c|c|c|c|}
\hline Technique & Material & Advantage & Disadvantage \\
\hline \multirow[t]{3}{*}{ full cast } & gold alloys & $\begin{array}{l}\text { easy workability, long term clinical approval } \\
\text { and longevity, exact marginal fit, } \\
\text { biocompatibility, wide range of indications }\end{array}$ & high price \\
\hline & cobalt/chromium alloys & $\begin{array}{l}\text { low price, low density, long term clinical } \\
\text { approval and longevity especially for partial } \\
\text { removable dentures }\end{array}$ & poor aesthetics \\
\hline & titanium & low price, low density, biocompatibility & $\begin{array}{l}\text { hard workability, poor aesthetics, plaque } \\
\text { retention }\end{array}$ \\
\hline \multirow[t]{3}{*}{ porcelain veneered } & gold alloys & $\begin{array}{l}\text { same as above, compatibility with approved } \\
\text { porcelains }\end{array}$ & $\begin{array}{l}\text { high price, dark bonding oxides if too high } \\
\text { base metal content }\end{array}$ \\
\hline & cobalt/chromium alloys & $\begin{array}{l}\text { same as above, compatible with approved } \\
\text { porcelains }\end{array}$ & dark bonding oxides, poor aethetics \\
\hline & titanium & same as above & $\begin{array}{l}\text { same as above, dark bonding oxides, } \\
\text { special porcelain }\end{array}$ \\
\hline electroforming & pure gold & $\begin{array}{l}\text { aesthetics, compatible with a wide range of } \\
\text { porcelains. exact marginal fit, small space } \\
\text { requirement, }\end{array}$ & high price, limited indication \\
\hline \multirow[t]{2}{*}{ all-ceramic } & $\begin{array}{l}\text { strengthened glass- } \\
\text { ceramics }\end{array}$ & aesthetics, biocompatibility & $\begin{array}{l}\text { high price, space requirement, seating with } \\
\text { composite, limited indication }\end{array}$ \\
\hline & glass infiltrated alumina & $\begin{array}{l}\text { aesthetics, seating with cement, } \\
\text { biocompatibility }\end{array}$ & $\begin{array}{l}\text { high price, space requirement, } \\
\text { limited indication }\end{array}$ \\
\hline \multirow[t]{3}{*}{ CAD/CAM } & alumina, zirconia & aesthetics, seating with cement & $\begin{array}{l}\text { high price, space requirement, limited } \\
\text { indication, fabrication only in service centers }\end{array}$ \\
\hline & gold alloys & same as above & $\begin{array}{l}\text { same as above, expensive, fabrication only } \\
\text { in service centers }\end{array}$ \\
\hline & titanium & $\begin{array}{l}\text { same as above, avoiding problems } \\
\text { with casting }\end{array}$ & $\begin{array}{l}\text { same as above, fabrication only in service } \\
\text { centers }\end{array}$ \\
\hline
\end{tabular}

(References M Maye, J Luo, Li Han, N Kariuki and CJ Zhong continued from page 82)

28 L. Han, M.M. Maye, F.L. Leibowitz, N.K. Ly, C.J. Zhong, J. Mater. Chem., 2001, 11, 1258

29 M.J. Hostetler, A.C. Templeton, R.W. Murray, Langmuir, 1999, 15, 3782

30 J. Luo, N. Kariuki, L. Han, M.M. Maye, L.W. Moussa, S.R. Kowaleski, F.L. Kirk, M. Hepel, C.J. Zhong, J. Phys. Chem. B, 2002, 106, 9313

31 W.X. Zheng, M.M. Maye, F.L. Leibowitz, C.J. Zhong, Anal. Chem., 2000, 72, 2190

32 N.N. Kariuki, L. Han, N.K. Ly, M.J. Peterson, M.M. Maye, G. Liu, C.J. Zhong, Langmuir, 2002, 18, 8255

33 M.M. Maye, S.C. Chun, L. Han, D, Rabinovich, C.J. Zhong, J. Am. Chem. SoC., 2002, 124, 4958

34 M.M. Maye, Y. Lou, C.J. Zhong, Langmuir, 2000, 16, 7520

35 Y. Lou, M.M. Maye, L. Han, J. Luo, C.J. Zhong, Chem. Commun., 2001, 473

36 J. Luo, M.M. Maye, Y. Lou, L. Han, M. Hepel, C.J. Zhong, Catal. Today, 2002, 77, 127

37 J. Luo, Y.B. Lou, M.M. Maye, C.J. Zhong, M. Hepel, Electrochem. Comm., 2001, 3, 172

38 M.M. Maye, J. Luo, Y. Lin, M.H. Engelhard, M. Hepel, C.J. Zhong, Langmuir, 2003, 19, 125
39 A.C. Templeton, F.P. Zamborini, W.P. Wuelfing, R.W. Murray, Langmuir, 2000, 16, 6682

40 U.A. Paulus, U. Endruschat, G.J. Feldmeyer, T.J. Schmidt, H. Bonnemann, R.J. Behm, J. Catal., 2000, 195, 383

41 J. Luo, V.W. Jones, M.M. Maye, L. Han, N.N. Kariuki, C.J. Zhong, J. Am. Chem. Soc., 2002, 124, 13988

42 A.P. Weber, S.K. Friedlander, J. Aerosol Science, 1997, 28, 179

43 C.T. Campbell, S.C. Parker, and D.E. Starr, Science, 2002, 298, 811

44 S. Wasmus, A. Kuever, J. Electroanal. Chem., 1999, 461, 14

45 G.Q. Lu, A. Wieckowski, Curr. Opin. Coll. Interf. Sci., 2000, 5, 95

46 M. Valden, X. Lai, D.W. Goodman, Science, 1998, 281, 1647

47 K.L. Ley, R.X. Liu, C. Pu, Q.B. Fan, N. Leyarovska, C. Segre, E.S. Smotkin, J. Electrochem. Soc., 1997, 144, 1543

48 A.J. Dickinson, L.P.L. Carrette, J.A. Collins, K.A. Friedrich, U. Stimming, Electrochim. Acta, 2002, 47, 3733

49 The Au/Pt ratio in the alloy nanoparticles can be regulated by the feed ratio of $\mathrm{AuCl}_{4}^{-}$vs. PtCl6. M.M. Maye, J. Luo, L. Han, N.N. Kariuki, C.J. Zhong, to be published. 